\title{
Research and Practice on Construction of Learning Society under the Perspective of Systematic Thinking
}

\author{
Jichuan Li \\ Primary Education College \\ Linyi University \\ Feixian, Shandong, China 273400
}

\begin{abstract}
Systematic thinking means using the viewpoint of whole situation to research on connection between key components of complex system. From the perspective of systematic thinking, the construction of learning society is a systematical engineering and needs integral design and system construction. On one hand, the government should make overall planning and set various types of educational institutions at all levels to provide the opportunity of lifelong learning for all the members of society; on the other hand, individuals should reasonably design learning plan to meet requirements of social development. Dominated by the government, a lifelong learning system that individuals actively participate in and everyone learns will be constructed.
\end{abstract}

Keywords -systematic thinking; learning society; construction; lifelong learning

\section{INTRODUCTION}

Nowadays, the society has increasingly showed the development characteristics of knowledge economy and information era. The rapid development of information, technology and economy is profoundly changing production mode and way of life of human society. Only through continuously improving learning ability and innovation ability can people effectively adapt to the rapid changes of social development, meet all kinds of opportunities and challenges that appear continuously, actively promote continuous development of society and economy and the progress of human civilization, and then realize harmonious development of human and society. Under this circumstance, it has become objective trend and inevitable choice of progress and development of human society to move toward learning society. Therefore, actively constructing learning society and making efforts to cultivate new-type talents who meet the requirements of learning society will become an important task to promote the development of society in our country. This research has important significance on us to fundamentally enter the learning society by 2020 .

\section{CONNOTATION OF S YSTEMATIC THINKING}

Systematic thinking derives from system dynamics. It requires people to follow the basic principles of systematic

The Shandong Provincial Social Science Planning Project "Research on Accommodation of Rural Vocational Education and Adult Education in the Counties under the Background of Agricultural Modernization" (14CJYJ07)

The staged achievement of Research on Preliminary Education in Rural Areas and Vocational Education Financing (2013JG324), the task of education science "12th Five-year" Plan in Shandong province. methodology when they observe the world, realize problems and solve problems. It enriches and perfects systematic methodology. Dornor, a cognitive psychologist in Germany, thinks that "systematic thinking is a unique and recognizable ability to use our reasoning according to individual situation"; he summarizes systematic thinking into a formula, namely: systematic thinking means systematic and complex situation plus full consideration for this situation. Now in circle of international system dynamics, people has been used to using "systematic thinking" to generalize basic principles and systematic perspective of systematic methodology.

Systematic thinking is a kind of framework of systematic method to analyze and research, solve dynamic and complex system problems. Its core is dialectical view of materialist system. Looking from the essence, it is in fact a kind of integrated and dynamic thinking method that analyzes, synthesizes feedback information inside and outside the system, nonlinear characteristics and influence of time delay. It emphasizes systematic, dialectical and development viewpoint and the relationship with continuous development and change between parts inside the system, as well as mutual effect between system and environment. It makes us see associated events instead of single event, forms that change gradually instead of momentary scene. That is to say, it shows the scene of dynamic development in front of our eyes instead of static snapshots.

\section{RESEARCH ON LEARNING SOCIETY CONSTRUCTION UNDER SYSTEMATIC THINKING}

Learning society was put forward by Robert Hutchins, a famous American scholar, in 1968 for the first time. Afterwards, scholars at home and abroad interpret learning society from different points of view. The scholar Zhu Xinjun in our country synthesizes statement of scholars at home and abroad on learning society and explains learning society from the perspective of ontology, and thinks "Learning society shall be an open, innovative and dynamic new type society that centers on social learners, base on lifelong education system, lifelong learning service system and learning organization, have basic characteristic of forming the culture of lifelong learning and can guarantee and meet basic rights of learning of social members and requirements of lifelong learning." In Outline of Educational Development, it regards "fundamentally realizing learning society" by 2020 as strategic 
target. In order to realize this strategic target, it is necessary to construct the system of learning society on the whole.

\section{A. Learning Society is an Education System that Runs through Lifetime}

Learning society is a lifelong education system from infant to old age, including three education systems, namely school education system, industry (enterprise) education system and social education system. The main task of school education system is education with record of formal schooling; the main task of industry education system is vocational certification education; the main task of social education system is cultural life education. The three kinds of education systems focus on different aspects and have mutual junction and undertake different education demands respectively to form lifelong education system of our country. The school education system will still be the main force of lifelong education system. The construction of lifelong education system is the basis to construct learning society. The optimization and combination of various systems inside the system can create the social environment that "there are places for learning everywhere and the learning contents are continuous", let each social member have the opportunity to receive education at all ages of lifetime and always keep the state of continuous learning as well as use learning to promote innovation. Everyone is learning in lifetime. It is never too late to learn.

\section{B. Learning Society is a Cultural System with Participation of All People}

Learning society is a cultural system from community to society, including community culture system, city (rural) culture system and national culture system. It is composed by four factors such as perfect cultural facilities, cultural undertakings of healthy development, sound cultural industry and rich cultural activities. Cultural facilities is the basic condition of cultural activities and basic place for selfdevelopment and leisure entertainment of social members, the important carrier of development of socialist culture and important front to spread advanced culture. Cultural undertakings of healthy development means paying attention to developing every cause such as philosophy and social science, literature and art, press and publications as well as radio, film and television, strengthening construction of cultural facilities such as libraries, museums, cultural centers, science and technology museums and places for activities of teenagers and meeting the increasingly growing spiritual and cultural needs of the masses. The sound cultural industry means having highly developed artistic performance industry, film and television industry, recording and video industry, and cultural recreation industry, cultural tourism industry, art training industry and artwork industry. Sound cultural industry can create various forms of carriers and colorful contents for learning society construction. Rich cultural activities mean paying adequate attention to enterprise culture, community culture, family culture, culture of old age, campus culture, children culture and festival culture, forming cultural activity system, carrying out cultural activities with rich contents, various forms that people are delighted to hear and see, meeting ever-growing requirements of cultural life of vast citizens and laying good mass base for national learning and lifelong learning.

\section{Learning Society is a Coordinated Organizational System from Top to Bottom}

Learning society is a hierarchical social system formed by learning society, learning city (country), learning community, learning organization and learning family. The hierarchical organization system is basically corresponding to the present system of administrative control from top to bottom. Learning family is the footstone of learning society, which is the top form. In this hierarchical system, different levels contain and depend on each other. The upper level can lead and guide other lower levels. Lower levels play the role of laying a foundation for the form of upper levels. Meanwhile, in specific administrative division, a relatively independent learning area can be formed through the support of policy system, guidance of education system and cultivation of cultural system. Making learning space at different levels coordinate mutually and develop harmoniously can provide good learning environment for learners and pave the way for learning society.

\section{EXPLORATION ON DEVELOPMENT PATH OF LEARNING SOCIETY UNDER SYSTEMATIC THINKING}

\section{A. Exert the Leading Role of Government and Construct Frame System of Learning Country}

The construction of learning society is to establish frame system of learning country with Chinese characteristics. The system of learning country includes learning individuals, learning community and learning society. Learning individuals is the tower footing of learning country. To cultivate learning individuals means letting each social member enjoy equal educational right and good education. The government should increase investment in education, popularize secondary education, energetically develop vocational education and reform higher education. Learning community is the connection of learning country. Constructing perfect learning community should develop local (community) economy, establish matched public facilities, improve living environment, enhance social service level and meet diversified material and cultural needs of people. Learning society is the ultimate goal of learning country. Realizing learning society, the country and the government must increase input to improve learning conditions of national people, increase places of education for national learning, strengthen cultural construction and give priority to developing public cultural places, stably improve population educational attainment, vigorously promote the increases of proportion of employed person who receive higher education and internet penetration rate, and continuously promote the increase of training rate of all employees as well as reinforce the vocational training of rural labor force.

\section{B. Update Learning Concept and Establish Lifelong Education System}

The lifelong education system is the core of construction of learning society. Realizing the change of educational concept is an important premise to construct lifelong education system. On value orientation of education, it is necessary to establish 
the concept of educational value that promotes the harmony and unity of social development and human development. The main objective of all forms of education at all levels is that students obtain lifelong learning ability, creative ability as well as survival and development ability. Besides, bring all kinds of school education and continuing education at all levels into the category of continuing education to provide all social members with the opportunity to learn "anytime and everywhere". Firstly, give full play to the effect of high quality education resources. At present, educational resources are mainly in school. The main form of school education is education with record of formal schooling. Exerting the main function of school education in construction of learning society is to integrally design all kinds of education with record of formal schooling at all levels and realize communication and cohesion of educational with record of formal schooling after junior high school. Secondly, realize the transform of various educational achievements and bring educational with record of formal schooling and education in professional qualification certificate into lifelong education system. The effective connection of academic certificate and qualification certificate makes all social members find a kind of effective way to improve educational level, vocational ability and selfdevelopment ability. Thirdly, actively carry out mutual recognition system, realize the connection of educational standard and employment standard and deepen education and teaching reforms. In 2002, Ministry of Labor and Social Security, Ministry of Education and Ministry of Personnel jointly issued Opinion on Further Promote Vocational Schools to Implement Professional Qualification Certificate System. The Opinion points out, "After being affirmed by labor security department and administrative department for education, the teaching contents of specialty in vocational schools conform to the requirements of national vocational standard. When graduates apply for participating in verification of professional technical ability below mediumgrade (including medium-grade), if the exam results of theory courses are qualified, it can be regarded that the verification of theoretical examination is qualified. The manipulation skills examination can be implemented according to relevant regulations of verification of professional technical ability". It provides important policy guarantee for mutual recognition of vocational education curriculum evaluation and identification of occupational qualifications as well as policy support for the establishment of lifelong education system and will certainly and immensely promote the construction of learning society in our country.

\section{Establish Credit Bank System and Set up the Service Platform of Learning Society}

"Credit" is a unit to calculate students' learning scores. The credit system is a teaching management system corresponding to scholastic year system. The credit system takes the specified the lowest total graduate credit as the standard to measure students' learning scores and graduation. Credit bank is the advanced form of credit system and the best form to integrally establish credit system. Credit Bank System (CBS) derives from South Korea and is a way of credit management that students earn credits through many forms such as learn courses in higher learning institution or social education training institution or pass the examination of credit certification of Ministry of Education, store it in the account that they register in credit management system; when it accumulates to a certain number, students can finally get higher education diploma. The credit bank can realize fixed deposit by installments of credit, break the barriers of various types of education and education forms and integrate all kinds of educational resources, realize the sharing of educational resources. It is the ideal pattern to realize lifelong learning, lifelong education and establish learning society.

\section{CONCLUSION}

The construction of learning society is a systems engineering. Using the theory of systematic thinking to look learning society, we will find that it is a compound system formed by multiple systems. Learning society is the education system throughout our life. In our lifetime, we need to receive family education, school education and social education, and it is a lifelong education from birth to death. Different education types form the entirety of life education. Learning society is a cultural system that all people participate in from community to society, including community culture system, city (rural) culture system and national culture system. It is an entirety formed by four factors, namely perfect cultural facilities, cultural undertakings of healthy development, sound cultural industry and rich cultural activities. Learning society is a coordinated organizational system from top to bottom and a hierarchical social system formed by learning society, learning city (country), learning community, learning organization and learning family. The construction of learning society is to bring the above systems into the entirety to realize integral design and construction, interrelation, interdependency and joint development of different systems.

\section{REFERENCES}

[1] Zhu Xinjun. Idea, Path and Countermeasures of Learning Society Construction [J], Modern Distance Education Research, 2011, (01)

[2] Li Jichuan. Construction of Lifelong Learning "Overpass" under the Perspective of Systematic Thinking [J], Chinese Vocational and Technical Education, 2011, (27)

[3] Qin Bing. Hu Rong. Research on Credit Bank System of Higher Education in South Korea [J], Comparative Education Study, 2009, (12)

[4] Jin Hongyi. Wang Lihong. Research on Connection of Vocational Education and Professional Qualification Certificate System [J], Continue Education Research, 2009, (07)

[5] Wang Xiping. Systematic Thinking on Motive Force of Cognition Development [J], Journal of Jiujiang University, 2007, (05)

[6] Chen Jingjing. Construction of Full Credit System Based on Credit Bank [J], Journal of Zhejiang University of Technology, 2010, (04) 